\title{
Theoretical study of the solvent effects on electronic properties of $2(1 \mathrm{H})$-quinoxalinone derivatives
}

\author{
Tourya Ghailane ${ }^{1}$, Rachida Ghailane ${ }^{1, *}$, Khadija Marakchi ${ }^{2}$, Brahim Lakhrissi $^{3}$, \\ Najia Komiha $^{2}$ and Abdelaziz Souizi ${ }^{1}$ \\ ${ }^{1}$ Laboratory of Organic, Organometallic and Theoretical chemistry, Department of Chemistry, \\ University of Ibn Tofail, Faculty of Science, Kenitra, Morocco \\ ${ }^{2}$ LS3ME-Equipe de Chimie Théorique et Modélisation, Département de Chimie, Université Mohammed V, \\ Faculté des Sciences B.P 1014, Rabat, Morocco \\ ${ }^{3}$ Laboratoire d'Agroressources et Génie des Procédés, Faculté des Sciences, Université Ibn Tofail, \\ Kénitra, Morocco
}

\begin{abstract}
The geometrical structures and electronic spectra of three quinoxalinone derivatives have been investigated theoretically by performing DFT and TDDFT calculations with standard basis sets containing polarization and diffuse functions. The solvent effect was taken into account using self-consistent isodensity polarized continuum model (SCIPCM); three polar solvents were considered. The effect of the solvent polarity on the geometries, solvation energies, dipole moment, the energy gap between HOMO and LUMO and UV-visible electronic transitions were examined for all studied compounds. The theoretical electronic spectrum of 2(1H)-quinoxalinone was compared with the experimental one. The experimental electronic spectrum recorded in ethanol exhibit three absorption bands respectively at 230, 280 and $350 \mathrm{~nm}$. The existence of these bands has been confirmed by TDDFT calculations for the studied quinoxalinone derivatives. The effects of solvent polarity and the nature of the substituent of the quinoxalinone on the displacement of the calculated absorption bands are discussed.
\end{abstract}

Keywords: Quinoxalines, UV-Visible, solvent effect, TDDFT, electronic transitions.

\section{Introduction}

Quinoxaline derivatives form an important class of benzoheterocycles which has received a good deal of interest in the last years due to their both biological properties and pharmaceutical applications 1. They are widely applied for medical use as antibiotics, antidepressants, anticonvulsants ${ }^{2-4}$, anticancer ${ }^{5}$, antibacterial ${ }^{6}$, and antitumor ${ }^{7-10}$ activities. They are also used in the agricultural field, and cosmetics ${ }^{11-14}$. Some quinoxaline derivatives act as DNA photocleavers ${ }^{15}$. The quinoxaline moiety exists in peptide antibiotics such as echinomycin and triostin $\mathrm{A}^{16}$ as well as in TANDEM which is known to intercalate bifunctionally into DNA ${ }^{17}$.

The use of the density functional theory (DFT) allows prediction of the molecular structure and spectroscopic properties as well as the tautomeric equilibria, of organic compounds ${ }^{18-22}$. The time dependent density functional theory (TDDFT) method has become the most widely used tool for theoretically evaluating the energies of the

*Corresponding author : Rachida Ghailane

Email address: ghailane_r@yahoo.fr

DOI : http://dx.doi.org/10.13171/mjc55/01606171600/ghailane excited state and to simulate the UV-vis and fluorescence spectra of organic compounds and metal complexes in solution ${ }^{23}, 24$. The calculations at B3LYP/6-31+G**, 6-311++ $\mathrm{G}^{* *}$ and $6-311 \mathrm{G}^{* *}$ levels are employed to determine and optimize all the tautomeric forms of 2-hydroxyquinoxaline 2OHQ. It is shown that the keto form of 2-OHQ is the most stable tautomer ${ }^{25}$. The QCISD method was also used to support relative energy values. The best results are obtained at the B3LYP/ $6-311++\mathrm{G}^{* *}$ level of the theory and compared with experiment. The detailed crystal data on 2-OHQ has been reported previously by N. Padjama et al. ${ }^{26}$.

The spectroscopic study and conformational analysis of the 2-quinoxaline carboxylic acid (2-QCA) were performed theoretically at B3LYP/6$31 \mathrm{G}^{*}$ level and experimentally by N. Prabavathi et al. ${ }^{27}$. The X-ray single crystallography was used to study the solid state molecular structure of 2,3-dihydroxyquinoxaline (DHQ). The tautomerism and spectral properties of DHQ are studied in the vacuum and in the presence of different solvents using the B3LYP/6-311++G(d, p) method ${ }^{28}$.

Received April 25 ${ }^{\text {th }}, 2016$

Accepted May 22 $2^{\text {nd }}, 2016$

Published June $17^{\text {th }}, 2016$ 
The geometrical structure and spectroscopic properties of 3-hydroxy-2-quinoxalinecarboxylic acid (3HQC) are studied experimentally and theoretically using B3LYP/6-311++G(d, p) by $S$. Yurdakul et al. ${ }^{29}$. Seven tautomers were determined among many stable conformations; the experimental spectra were concordant with the theoretical data of two tautomers. The authors have concluded that the stable tautomeric forms are stabilized by intramolecular $\mathrm{O}-\mathrm{H}$.... $\mathrm{O}$ and $\mathrm{O}-\mathrm{H} . . . \mathrm{N}$ hydrogen bond type.

The aim of this study is to examine the effect of the solvent polarity and the effect of the introduction of polarization functions and diffuse functions in the standard basis on the geometrical structures and on the electronic spectra of the three derivatives quinoxaline. The optimized geometrical structures, the absorption wavelengths, excitations energies of three quinoxaline derivatives, $2(1 \mathrm{H})$-quinoxalinone HQ (Fig.1), 3-(Methyl)-2-quinoxalinone $\mathbf{C H}_{3} \mathbf{Q}$ and 3-(Formyl)-2-quinoxalinone CHOQ (Scheme1),

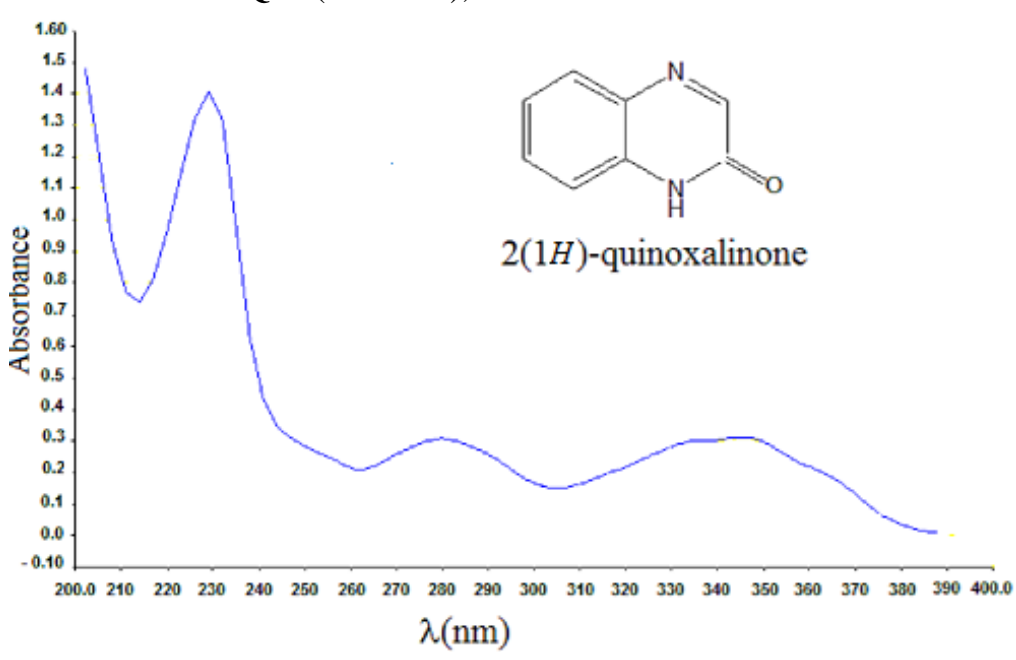

Figure 1. Experimental absorption spectrum of HQ in ethanol.<smiles>Cc1nc2ccccc2[nH]c1=O</smiles>

3-methyl-2-Quinoxalinone $\left(\mathbf{C H}_{\mathbf{3}} \mathbf{Q}\right)$ have been carried out using DFT and TDDFT theories combined with standard basis sets $6-31 G^{*}$, $6-31+\mathrm{G}^{* *}, 6-311++\mathrm{G}^{* *}$ and $6-311 \mathrm{G}^{* *}$ which are proved to be sufficient for similar studies. The use of the Time-Dependent Density Functional Theory (TDDFT) method turns out reliable for the determination of the electronic spectra ${ }^{30,31}$. The choice of the four basis could be justified by the fact that in a previous study of FT-IR and TF-Raman spectra of Keto and enol forms of HQ at B3LYP// 6-

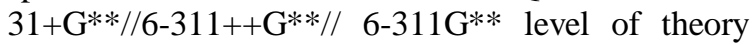
give a good agreement theory-experiment, one also chooses to use the $4^{\text {th }}$ basis set $6-31 G^{*}$ to check if it is sufficient to well describe the geometrical structure of the HQ. We have decided to focus our interest on the solvent polarity effects on UV-visible spectra for the three quinoxaline derivatives. On the other hand, the substitution effect was deduced by comparing the wavelengths $\left(\lambda_{\max }\right)$ of the maximum absorption peaks obtained from the electronic spectra of the three derivatives.

Scheme. 1. Chemical structures of the investigated quinoxaline derivatives.

Illustration of the electronics properties of these derivative can be provided from the electronic parameter values such as dipole moment and energy gap, which were obtained using the same level of theory in the both gas and solvated phases.

\footnotetext{
Synthesis part and experimental UV spectra of $2(1 H)$-quinoxalinone

2(1H)-quinoxalinone $\mathbf{H Q}$ was synthesized in the laboratory of one of the authors, its synthesis
}

and purification methods have been described elsewhere ${ }^{32}$. Spectrograde ethanol is used as it is. Absorption spectra are observed with a spectrophotometer (Cary 5G, UV-visible-NIR).

The ultraviolet-visible spectra of $2(1 H)$ quinoxalinone are given in Fig. 1. 


\section{Experimental Section}

Apparatus for identification of quinoxalin-2 $(1 \mathrm{H})$ one. ${ }^{1} \mathrm{H}$ NMR spectra in DMSO- $\mathrm{d}_{6}$ was taken on Bruker WB-300, and chemical shifts given in ppm downfield from TMS and melting point was determined on melting Point Apparatus (Jencons 9200) and is uncorrected.

Synthesis of $2(1 H)$-quinoxalinone ${ }^{32}$ : a mixed solution of o-phenylenediamine $(2.16 \mathrm{~g}, 20 \mathrm{mmol})$ and glyoxylic acid (2.3 g, $25 \mathrm{mmol}$ in n-butanol (60 $\mathrm{mL}$ ) was refluxed for $5 \mathrm{hrs}$. After standing in a freezer for one night, the formed solid was filtered under reduced pressure and washed with cyclohexane $(20 \mathrm{~mL})$ to give light yellow crystal of $2(1 \mathrm{H})$ quinoxalinone $\left(2.28 \mathrm{~g}\right.$, yield $78 \%$; mp $\left.236-238^{\circ} \mathrm{C}\right)$.

Spectral data of $2(1 H)$-quinoxalinone $1 \mathrm{H}$ NMR $\left(\right.$ DMSO-d $\left._{6}\right), \delta(\mathrm{ppm}): 12.45(\mathrm{~s}, 1 \mathrm{H}, \mathrm{N}-H), 7.30-7.80$ (m, 4H, Ar- $H$ ), 8.18 (s, 1H, C-H).

\section{Computational details}

Ground-state electronic structure calculations of quinoxalinone derivatives are performed in vacuum without any symmetry constraint using the Density Functional Theory (DFT) with the Beck's three parameter exchange functional and the Lee-YangParr non-local correlation functional (B3LYP) ${ }^{33-35}$. This level of theory was shown to be reliable to geometric optimization and the determination of the energy parameters for a wide variety of systems. Four basis sets of atomic orbitals, 6-31G(d), 6$311 \mathrm{G}(\mathrm{d}, \mathrm{p}), \quad 6-31+\mathrm{G}(\mathrm{d}, \mathrm{p})$ and $6-311++\mathrm{G}(\mathrm{d}, \mathrm{p})$ as implemented in Gaussian 03 program package ${ }^{36}$, were used throughout this study. These basis sets contain polarization functions allowing to describe correctly the intramolecular $\mathrm{H}$ bonding and the excited states. The stability of the optimized geometry of the molecular structure was confirmed by harmonic vibrational wavenumbers calculated using analytic second derivatives which have shown the absence of imaginary frequency modes. For all performed calculations, in this study, solvent effects were taken into account by self-consistent reaction field SCRF method using a self-consistent isodensity polarized continuum model (SCIPCM) ${ }^{37}$. Moreover, three solvents THF, ethanol (EtOH) and acetonitrile $(\mathrm{MeCN})$ whose dielectric constants $(\varepsilon)$ are 7.426, 24.852 and 35,688 respectively ${ }^{36}$, are considered in order to discuss the polarity effects on the electronic

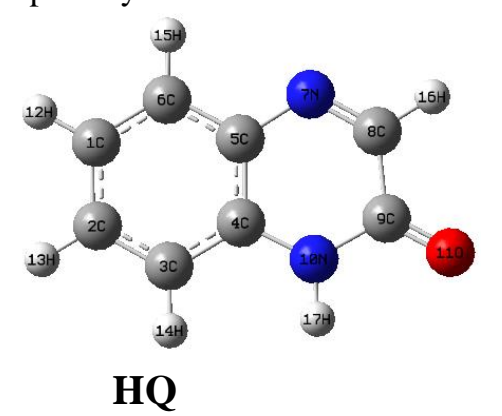

parameters and the UV-visible electronic transitions for the studied molecules. Indeed, the solute-solvent interactions have a direct and significant influence on UV-visible spectra. As a consequence, a reliable theoretical study of electronic spectra cannot be performed without a proper treatment of solvation. Time-dependent density functional theory (TDDFT) calculations with B3LYP functional have been performed for quinoxaline derivatives, in the gas, and in solution, on the basis of fully optimized ground state geometrical structures in the vacuum at the same level of theory. These calculations allow us to investigate the electronic absorption properties and to get the excitation energies. Otherwise, in order to correctly reproduce the UV spectra of quinoxaline derivatives, vertical excitation energies are computed for the 30 first singlet excited states.

\section{Results and Discussion}

\section{Molecular geometry}

The Optimized geometries of studied derivatives are determined by complete optimization, in vacuum, using B3LYP functional. The geometrical structure of HQ (Fig.2) has been already optimized with B3LYP method using 6-311++G(d, p), 6-31+G(d, p) and $6-311 \mathrm{G}(\mathrm{d}, \mathrm{p})$ basis sets, it is shown that the keto form of 2-OHQ is the most stable tautomère ${ }^{25}$. In the present work, the standard basis $6-31 \mathrm{G}(\mathrm{d})$ was also used in order to verify whether it is possible to better describe the geometrical structure of this molecule while reducing the computational cost. The complete geometrical optimization of $\mathbf{C H}_{3} \mathbf{Q}$ and CHOQ derivatives (Fig. 2) were carried out using B3LYP combined with the four standard basis 6-31G(d) (B), 6-311G(d,p) (B2), 6-31+G(d,p) (B1) and $6-311++G(d, p)$ (B3) in vacuum. For each optimized structure, the calculation of the vibrational frequencies was performed and shows that there is no imaginary frequency. Consequently, each geometrical structure corresponds to a stationary point on the potential energy surface. The optimized structures of three derivatives with the label of atoms are presented in Fig. 2. Moreover, the exact values of some selected bond lengths and bond angles of these derivatives were collected in Table 1 . In the literature, there are no exact X-ray crystal structures for $\mathbf{C H}_{3} \mathbf{Q}$ and $\mathbf{C H O Q}$ molecules; thus, they are compared with the experimental data of the HQ molecule ${ }^{26}$.

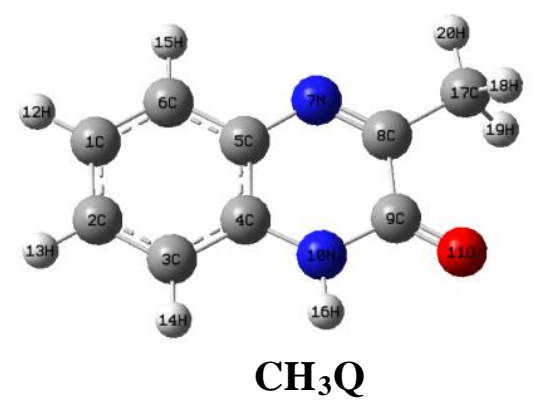




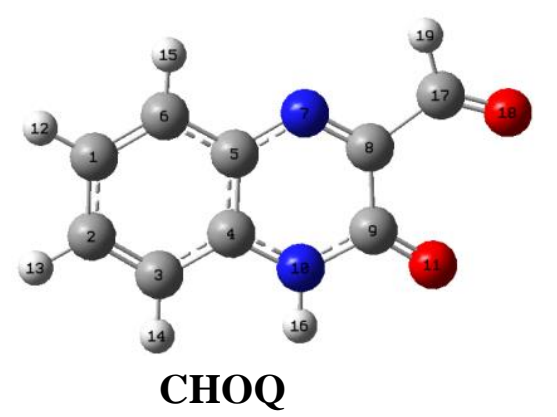

Figure 2. Optimized molecular structures of quinoxalinone derivatives.

Table 1. Bond length $(\AA)$ and Bond angle $\left(^{\circ}\right)$ of the studied quinoxaline derivatives $\mathbf{H Q}, \mathbf{C H}_{3} \mathbf{Q}$ and $\mathbf{C H O Q}$ calculated at B3LYP using four basis sets 6-31G(d) (B), 6-311G(d,p) (B2), 6-31+G(d,p) (B1) and $6-311++\mathrm{G}(\mathrm{d}, \mathrm{p})(\mathrm{B} 3)$ in gas phase.

\begin{tabular}{|c|c|c|c|c|c|c|c|c|c|c|}
\hline \multicolumn{3}{|c|}{ HQ } & \multicolumn{2}{|c|}{$\mathrm{CH}_{3} \mathrm{Q}$} & \multirow[b]{2}{*}{ B3 } & \multirow[b]{2}{*}{ B } & \multicolumn{2}{|c|}{ CHOQ } & & \multirow{2}{*}{$\frac{H Q}{\text { X-Ray }}$} \\
\hline Basis sets & B & B & B2 & B1 & & & B2 & B1 & B3 & \\
\hline $\begin{array}{l}\text { Bond lengh } \\
\text { (̊) }\end{array}$ & 1.404 & 1.404 & 1.402 & 1.406 & 1.402 & 1.407 & 1.409 & 1.409 & 1.405 & 1.403 \\
\hline $\mathrm{C} 1-\mathrm{C} 2$ & 1.389 & 1.389 & 1.386 & 1.390 & 1.387 & 1.388 & 1.389 & 1.389 & 1.385 & 1.363 \\
\hline $\mathrm{C2}-\mathrm{C3}$ & 1.402 & 1.402 & 1.400 & 1.403 & 1.400 & 1.403 & 1.405 & 1.405 & 1.402 & 1.401 \\
\hline C3-C4 & 1.416 & 1.414 & 1.411 & 1.414 & 1.411 & 1.419 & 1.419 & 1.419 & 1.415 & 1.411 \\
\hline C4-C5 & 1.405 & 1.405 & 1.403 & 1.407 & 1.404 & 1.409 & 1.411 & 1.410 & 1.4081 .381 & 1.402 \\
\hline C5-C6 & 1.387 & 1.387 & 1.384 & 1.389 & 1.385 & 1.384 & 1.385 & 1.385 & 1.4921 .375 & 1.373 \\
\hline C6-C1 & 1.481 & 1.492 & 1.493 & 1.493 & 1.493 & 1.491 & 1.492 & 1.492 & 1.3731 .398 & 1.465 \\
\hline C8-C9 & 1.383 & 1.383 & 1.382 & 1.384 & 1.383 & 1.376 & 1.377 & 1.377 & 1.2991 .212 & 1.372 \\
\hline C4-N10 & 1.389 & 1.388 & 1.387 & 1.388 & 1.386 & 1.375 & 1.375 & 1.375 & 2.275 & 1.386 \\
\hline C5-N7 & 1.390 & 1.385 & 1.383 & 1.382 & 1.382 & 1.400 & 1.397 & 1.397 & 2.451 & 1.342 \\
\hline C9-N10 & 1.292 & 1.296 & 1.292 & 1.298 & 1.293 & 1.303 & 1.304 & 1.304 & & 1.287 \\
\hline C8-N7 & 1.223 & 1.225 & 1.219 & 1.229 & 1.221 & 1.217 & 1.220 & 1.220 & & 1.239 \\
\hline C9-011 & 2.293 & 2.286 & 2.280 & 2.284 & 2.279 & 2.280 & 2.275 & 2.279 & & \\
\hline N10...O11 & 2.490 & 2.475 & 2.471 & 2.472 & 2.471 & 2.452 & 2.450 & 2.450 & & \\
\hline \multicolumn{11}{|l|}{ H16...O11 } \\
\hline \multicolumn{11}{|l|}{ Bond angle $\left({ }^{\circ}\right)$} \\
\hline C2C1C6 & 119.8 & 119.8 & 119.8 & 119.9 & 119.9 & 119.7 & 119.7 & 119.8 & 119.8 & 120.0 \\
\hline $\mathrm{C} 3 \mathrm{C} 4 \mathrm{C} 5$ & 120.3 & 120.5 & 120.4 & 120.6 & 120.5 & 120.1 & 120.0 & 120.2 & 120.1 & 119.4 \\
\hline $\mathrm{C} 1 \mathrm{C} 2 \mathrm{C} 3$ & 120.9 & 120.8 & 120.8 & 120.7 & 120.7 & 121.2 & 121.2 & 121.2 & 121.2 & 120.8 \\
\hline C4C5C6 & 119.1 & 118.9 & 118.9 & 118.9 & 118.9 & 119.3 & 119.3 & 119.4 & 119.4 & 119.4 \\
\hline C6C5N7 & 119.4 & 119.4 & 119.5 & 119.5 & 119.5 & 119.6 & 119.6 & 119.6 & 119.7 & 119.2 \\
\hline C3C4N10 & 122.4 & 122.5 & 122.6 & 122.5 & 122.5 & 122.8 & 122.8 & 122.8 & 122.8 & 122.3 \\
\hline C4N10C9 & 124.3 & 124.4 & 124.4 & 124.4 & 124.4 & 125.4 & 125.3 & 125.3 & 125.3 & 122.5 \\
\hline C5N7C8 & 118.6 & 119.7 & 119.9 & 120.1 & 120.1 & 120.4 & 120.7 & 120.7 & 120.8 & 117.5 \\
\hline N10C9O11 & 122.5 & 122.1 & 122.2 & 121.9 & 122.1 & 121.0 & 120.9 & 120.9 & 121.1 & 121.8 \\
\hline C8C9O11 & 124.7 & 124.2 & 124.2 & 124.1 & 124.1 & 126.9 & 126.7 & 126.7 & 126.7 & 122.6 \\
\hline
\end{tabular}

The geometrical parameters values calculated at B3LYP/6-31G (d) level of theory was shown to be in good agreement with the experimental data of $\mathbf{H Q}$. Therefore, the use of this level of theory seems to be sufficient to correctly describe the geometrical structure of similar molecules. The geometrical structure of benzenic cycle of quinoxaline was weakly affected by the substitution of $\mathrm{H}$ in $\mathbf{H Q}$ molecule by $\mathrm{CH}_{3}$ or $\mathrm{CHO}$. The bond lengths presented in Table 1 are generally longer than those obtained by X-ray. The larger deviations of the calculated values from the experimental data are $0.028 \AA$ and $0.056 \AA$ observed respectively for C8-C9 and C9-N10. While the value of the bond length $\mathrm{C} 9-\mathrm{O} 11$ is shorter than that given by the experiment of about $0.027 \AA$.

In the benzene ring, $\mathrm{C} 2 \mathrm{C} 1 \mathrm{C} 6$ and $\mathrm{C} 4 \mathrm{C} 5 \mathrm{C} 6$ bond angles are slightly smaller than 120 and $\mathrm{C} 1 \mathrm{C} 2 \mathrm{C} 3$ and C3C4C5 are slightly larger than 120 . The value of the bond angle in the benzene ring is between 119.7 and $120.4^{\circ}$. On the other side, within the heterocyclic ring, the bond angles vary between $119.5^{\circ}$ and 
$124.4^{\circ}$ for $\mathbf{C H}_{\mathbf{3}} \mathbf{Q}$ and $119.7^{\circ}$ and $125.3^{\circ}$ for $\mathbf{C H O Q}$. The larger deviation from the experience was $2.8^{\circ}$ observed for the C4N10C9 bond angle calculated using 6-311++G (d, p) (B3) basis for CHOQ. For the bond angle outside the heterocyclic ring, the bond angle C8C9O11 for CHOQ is larger by $4.1^{\circ}$ than the experiment.

Both molecules HQ and CHOQ are planar, all dihedral angle values are equal to 0 or $180^{\circ}$; whereas, this planarity is broken by the presence of the $\mathrm{CH}_{3}$ substituent in the case of $\mathbf{C H}_{3} \mathbf{Q}$ derivative. The structural analysis reveals the presence of weak intermolecular hydrogen bond interactions between O11...H16-N10 in the studied molecules. The distance between $\mathrm{O} 11 \cdots \mathrm{N} 10$ is about $2.29 \AA$, this value is $<3.0 \AA$ in accordance of a hydrogen interaction ${ }^{38}$. The values of the hydrogen bond (O11...H16-N10) observed in the three molecules CHOQ, $\mathbf{C H}_{3} \mathbf{Q}$ and $\mathbf{H Q}$ are respectively $2.49 \AA$, $2.47 \AA$ and $2.45 \AA$, values are in good agreement with the value $2.478 \AA$ given by S. Sudha et al ${ }^{39}$ for an intramolecular $\mathrm{C}-\mathrm{H}$....O hydrogen bond, observed in the dibenzalacetone (DBA) molecule, between oxygen atom of $\mathrm{C}=\mathrm{O}$ group and hydrogen atom of alkene group. We can notice that a slight increase of interaction observed in CHOQ molecule is translated by the shorter hydrogen bond. The table 1 shows that the values of hydrogen bond remain almost constant for the three quinoxaline derivatives, by adding the diffuse function in the basis sets of atomic orbitals.

\section{Solvation energy and electronics parameters}

The solvation energy $\left(\Delta \mathrm{E}_{\mathrm{sol}}\right)$ is estimated by the difference between the total energy obtained in the solvent and that calculated in vacuum, it is defined as following:

$$
\Delta \mathbf{E}_{\text {sol }}=\mathbf{E}_{\mathbf{T}}(\text { in solution })-\mathbf{E}_{\mathbf{T}}(\text { in vacuum })
$$

The solvation energies reported in Table 2 show that the calculations, using $6-31+\mathrm{G}(\mathrm{d}, \mathrm{p})$ basis, lead to a better stabilization for the three derivatives. The $\Delta \mathrm{E}_{\mathrm{sol}}$ values are the largest one for the most polar solvent MeCN compared to those obtained in $\mathrm{EtOH}$ and THF solvents. In the presence of the solvent, this stabilization is less important when the $\mathrm{H}$ in the position $\alpha$ to keto is substituted by $\mathrm{CH}_{3}$ group rather than by $\mathrm{CHO}$ substituent. One can also notice that the polarity of the solvent increases the solvation energy and the difference between the $\Delta \mathrm{E}_{\mathrm{sol}}$ values obtained in THF and MeCN solvents, using 6-31+G(d,p) (B1) basis, is about $2 \mathrm{kcal}$ for CHOQ and $1 \mathrm{kcal}$ for $\mathbf{C H}_{3} \mathbf{Q}$ and $\mathbf{H Q}$. To conclude, the most important stabilization caused by the solvent polarity effects is observed for CHOQ. It is well known that the solvent interact with the polarized bond and its effect is more important when the molecule contains more polarized bonds, and CHOQ contains two $\mathrm{C}=\mathrm{O}$ groups strongly polarized. Furthermore, considering the $\Delta \mathrm{E}_{\mathrm{sol}}$ values obtained with $\mathrm{MeCN}$ using 6-31+G(d,p) (B1) basis, the difference between $\Delta \mathrm{E}_{\mathrm{sol}}$ values of $\mathbf{C H O Q}$ and that of $\mathrm{HQ}$ is equal to $3.74 \mathrm{kcal}$, while the difference between $\Delta \mathrm{E}_{\mathrm{sol}}$ values of $\mathbf{C H}_{3} \mathbf{Q}$ and that of $\mathbf{H Q}$ is equal to- $0.78 \mathrm{kcal}$. One can deduce that when we replace $\mathrm{H}$ by an electrodonor group like $\mathrm{CH}_{3}$, the solvation energy decreases, conversely the substitution of $\mathrm{H}$ by an electro-attractor group $\mathrm{CHO}$ leads to an increase of the solvation energy.

Table 2. Total energies (in a.u) and solvation energy $\Delta \mathrm{E}_{\mathrm{sol}}$ (in kcal) of the three quinoxaline derivatives.

\begin{tabular}{|c|c|c|c|c|c|c|c|}
\hline & & HQ & & $\mathrm{CH}_{3} \mathrm{Q}$ & & CHOQ & \\
\hline Basis & phase & $\mathrm{E}(\mathrm{a} . \mathrm{u})$ & $\Delta \mathrm{E}_{\mathrm{sol}}$ & $\mathrm{E}(\mathrm{a} . \mathrm{u})$ & $\Delta \mathrm{E}_{\mathrm{sol}}$ & $\mathrm{E}(\mathrm{a} . \mathrm{u})$ & $\Delta \mathrm{E}_{\mathrm{sol}}$ \\
\hline \multirow[t]{4}{*}{ 6-31G(d) } & Gas & -493.203959 & --- & -532.528622 & --- & -606.519292 & --- \\
\hline & $\mathrm{THF}$ & -493.212961 & 5.65 & -532.537019 & 5.27 & -606.532440 & 8.26 \\
\hline & $\mathrm{EtOH}$ & -493.214541 & 6.64 & -532.538547 & 6.23 & -606.534838 & 9.75 \\
\hline & $\mathrm{MeCN}$ & -493.214792 & 6.80 & -532.538792 & 6.39 & -606.535222 & 9.99 \\
\hline \multirow{4}{*}{ 6-311G(d,p) } & Gas & -493.328046 & --- & -532.663287 & --- & -606.673760 & --- \\
\hline & THF & -493.336859 & 5.53 & -532.671314 & 5.03 & -606.686661 & 8.09 \\
\hline & $\mathrm{EtOH}$ & -493.338404 & 6.50 & -532.672762 & 5.95 & -606.689012 & 9.57 \\
\hline & $\mathrm{MeCN}$ & -493.338649 & 6.66 & -532.672994 & 6.09 & -606.689388 & 9.80 \\
\hline \multirow[t]{4}{*}{ 6-31+G(d,p) } & Gas & -493.235650 & --- & -532.563418 & --- & -606.554619 & --- \\
\hline & THF & -493.245144 & 5.95 & -532.571823 & 5.28 & -606.568943 & 8.99 \\
\hline & $\mathrm{EtOH}$ & -493.246817 & 7.01 & -532.573344 & 6.23 & -606.571588 & 10.65 \\
\hline & $\mathrm{MeCN}$ & -493.247083 & 7.17 & -532.573587 & 6.39 & -606.572014 & 10.91 \\
\hline 6- & Gas & -493.337877 & --- & -532.672462 & --- & -606.685597 & --- \\
\hline \multirow{3}{*}{$311++G(d, p)$} & $\mathrm{THF}$ & -493.347197 & 5.86 & -532.680733 & 5.19 & -606.699508 & 8.72 \\
\hline & $\mathrm{EtOH}$ & -493.348837 & 6.87 & -532.682233 & 6.13 & -606.702071 & 10.33 \\
\hline & $\mathrm{MeCN}$ & -493.349098 & 7.03 & -532.682474 & 6.27 & -606.702482 & 10.61 \\
\hline
\end{tabular}

6-31G(d) ; 6-311G(d,p) ; 6-31+G(d,p) and 6-311++G(d,p) correspond, in the text, to B; B2; B1 and B3 respectively. 


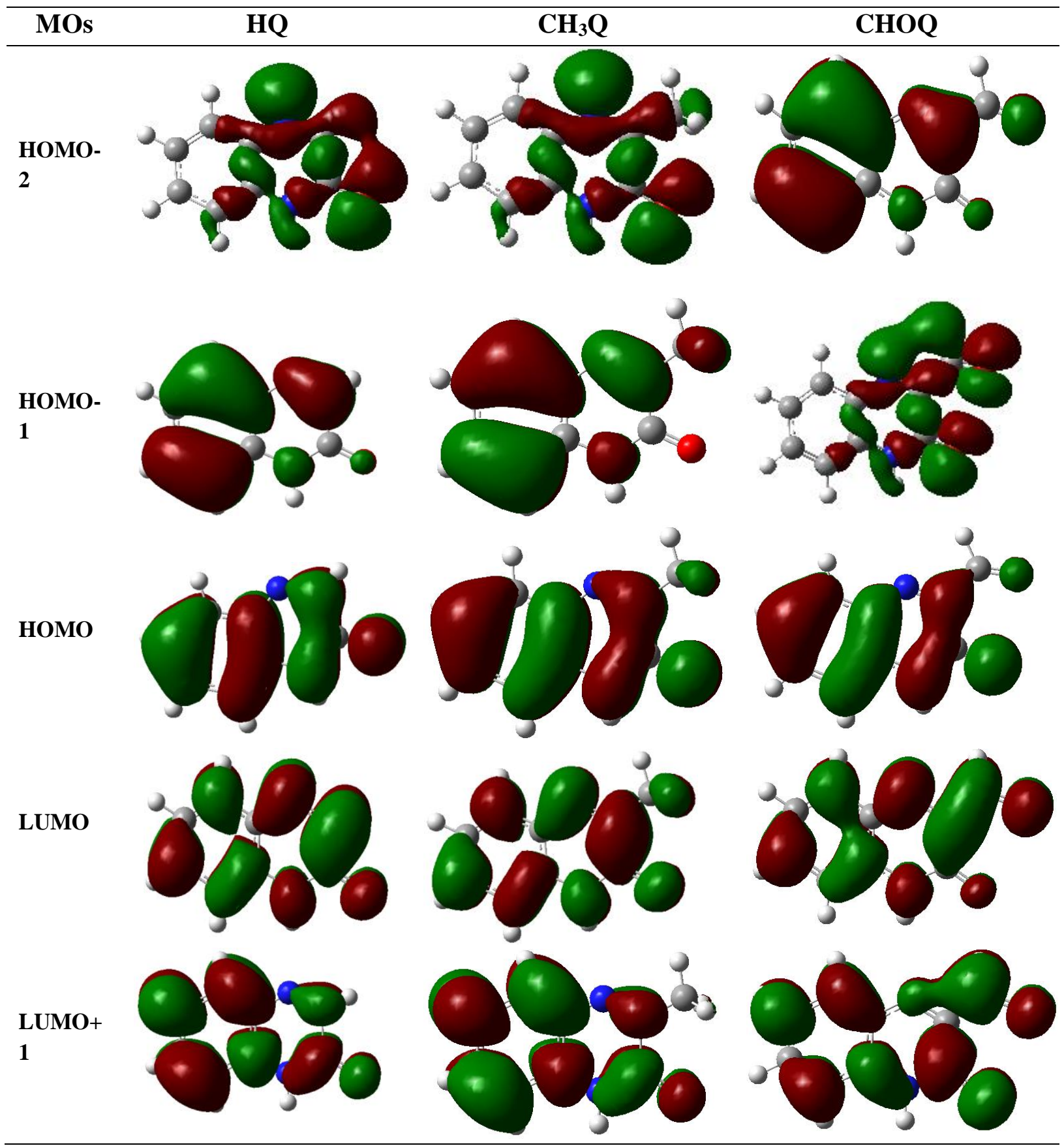

Figure 3. Isodensity plots of the frontier orbitals of the quinoxalines derivatives.

The dipole moment and energy gap between HOMO and LUMO are often used to discuss the physical and chemical behavior of molecular system such as activity, reactivity, optical and electrical properties. Table 3 shows that the largest dipole moment values are given with the calculations using $6-31+\mathrm{G}(\mathrm{d}, \mathrm{p})(\mathrm{B} 1)$ basis for the three derivatives and the dipole moment values in a solvent are larger than that in a vacuum, and, they increase with the solvent polarity. The solvent effect on the dipole moment is notable for CHOQ, this can be shown by the difference, between the values obtained in gas and in $\mathrm{MeCN}$ (the most polar solvent), which is approximately $2.5 \mathrm{D}$, while this difference is evaluated to 1.1 and $1.3 \mathrm{D}$ for $\mathbf{H Q}$ and $\mathbf{C H}_{3} \mathbf{Q}$ respectively. Moreover, the dipole moment value for
CHOQ is the largest one (10.08D) by comparison with 5.02 and 4.44 D values obtained for HQ and $\mathrm{CH}_{3} \mathbf{Q}$ respectively.

According to the frontier molecular orbital (FMO) theory, the formation of a transition state is due to an interaction between the frontier orbitals (HOMO and LUMO) of reactants ${ }^{40}$. The energy of the HOMO is directly related to the ionization potential and the energy of the LUMO is directly related to the electron affinity. The high value of HOMO energy is likely to indicate a tendency of the molecule to donate electrons to appropriate acceptor molecule of low empty molecular orbital energy. A low value of LUMO energy shows more probability to accept electrons. So, the gap energy, i.e. the 
difference in energy between the HOMO and LUMO, is an important stability index. It is a critical parameter in determining molecular electrical transport properties because it is a measure of electron conductivity. Low gap value refers to the higher electronic transition and vice versa. The energy gap is reported in Table 3 and the LUMO and HOMO plot are shown in Fig. 3. The HOMO has a pronounced $\pi$ character localized on $\pi$-system of quinoxaline moiety and the oxygen atom of carbonyl group while the LUMO has antibonding $\pi$ character localized mostly on $\mathrm{N}-\mathrm{C}$ and $\mathrm{N}-\mathrm{H}$ bonds in the heterocyclic ring, benzene and oxygen atom of $\mathrm{C}=\mathrm{O}$ group. The smaller energy gap values (Table 3) are calculated with B1 basis for the three quinoxaline derivatives in vacuum and in solution. For the studied quinoxaline derivatives, the HOMO-LUMO gap of quinoxaline derivatives in a polar solvent are smaller than that in the vacuum, this indicates that the solvent polarity effects stabilize the LUMO and destabilize the HOMO. In the $\mathrm{MeCN}$ polar solvent, the energy gap is equal to $3.67 \mathrm{eV}$, lower than the energy gap 4.39 and $4.28 \mathrm{eV}$ obtained respectively for $\mathbf{C H}_{3} \mathbf{Q}$ and $\mathbf{H Q}$. This result indicates that the transitions from the ground state to excited states are easier in CHOQ molecule than in $\mathbf{C H}_{3} \mathbf{Q}$ and $\mathbf{H Q}$. Therefore, the substitution effect plays an important role in molecular electrical transport properties.

\section{UV-Vis spectra analysis}

UV-visible absorption spectra of the quinoxaline derivatives were calculated by the TDDFT method in three polar solvents to predict the effect of solvent on the absorption intensities as well as on the corresponding wavelengths values.

The time-dependent density functional method is able to reproduce the absorption wavelengths which correspond to vertical electronic transitions computed on the ground state geometry, the solvent effect could also be studied ${ }^{41-43}$. In the present study, the TDDFT calculations were performed using B3LYP function and different standard basis set 6-31G(d), 6-31+G(d, p), 6-311++G(d, p), 6-311G(d, p) in order to determine the Low-lying excited states of the studied molecules. In these calculations, we started from the gas phase optimized geometries of the $\mathbf{H Q}, \mathbf{C H}_{3} \mathbf{Q}$ and $\mathbf{C H O Q}$ derivatives using the same level of theory. The three derivatives were considered so that the effect of electro-donor or electro-attractor of the substituent group on the absorption spectrum can be discussed. The absorption wavelengths $\left(\lambda_{\max }\right)$, oscillator strengths (f), excitation energies $(\Delta \mathrm{E})$ and dominant coefficient of the excitation, in the vacuum and in the solution, are calculated for the three derivatives are regrouped in Tables 4-6. The electronic spectra are illustrated in Fig. $4(a, b, c)$. Only the three first vertical excitations were considered, the corresponding oscillator strengths are greater than $0.08,0.1$ and 0.07 for $\mathbf{H Q}, \mathbf{C H}_{3} \mathbf{Q}$ and $\mathbf{C H O Q}$ derivatives respectively.

Table 3. Dipole moment $\mu$ (in Debye), energy gap $\Delta \mathrm{E}$ (HOMO-LUMO) (in $\mathrm{eV}$ ) of the three quinoxaline derivatives.

\begin{tabular}{|c|c|c|c|c|c|c|c|}
\hline \multirow[b]{2}{*}{ Basis } & \multirow[b]{2}{*}{ phase } & \multicolumn{2}{|l|}{ HQ } & \multicolumn{2}{|l|}{$\mathrm{CH}_{3} \mathrm{Q}$} & \multicolumn{2}{|l|}{ CHOQ } \\
\hline & & $\mu$ & $\Delta \mathrm{E}$ & $\mu$ & $\Delta \mathrm{E}$ & $\mu$ & $\Delta \mathrm{E}$ \\
\hline \multirow[t]{4}{*}{$6-31 G(d)$} & Gas & 3.9807 & 4.364 & 3.1210 & 4.462 & 6.9851 & 3.779 \\
\hline & THF & 5.0226 & 4.338 & 4.0364 & 4.442 & 8.9477 & 3.717 \\
\hline & $\mathrm{EtOH}$ & 5.2028 & 4.330 & 4.1992 & 4.437 & 9.2891 & 3.699 \\
\hline & $\mathrm{MeCN}$ & 5.2314 & 4.329 & 4.2252 & 4.435 & 9.3433 & 3.697 \\
\hline \multirow[t]{4}{*}{ 6-311G(d,p) } & Gas & 3.9240 & 4.365 & 3.0645 & 4.472 & 6.9170 & 3.799 \\
\hline & $\mathrm{THF}$ & 5.2579 & 4.331 & 3.9199 & 4.454 & 8.8441 & 3.744 \\
\hline & $\mathrm{EtOH}$ & 5.1122 & 4.334 & 4.0714 & 4.450 & 9.1783 & 3.728 \\
\hline & $\mathrm{MeCN}$ & 5.1400 & 4.333 & 4.0955 & 4.449 & 9.2312 & 3.725 \\
\hline \multirow[t]{4}{*}{$6-31+G(d, p)$} & Gas & 4.3343 & 4.319 & 3.3325 & 4.420 & 7.5377 & 3.775 \\
\hline & $\mathrm{THF}$ & 5.4129 & 4.293 & 4.2518 & 4.402 & 9.6559 & 3.691 \\
\hline & $\mathrm{EtOH}$ & 5.5960 & 4.286 & 4.4142 & 4.398 & 10.0205 & 3.674 \\
\hline & $\mathrm{MeCN}$ & 5.6251 & 4.285 & 4.4400 & 4.397 & 10.0783 & 3.671 \\
\hline \multirow[t]{4}{*}{ 6-311++G(d,p) } & Gas & 4.2453 & 4.330 & 3.2392 & 4.434 & 7.3873 & 3.801 \\
\hline & $\mathrm{THF}$ & 5.4129 & 4.293 & 4.1262 & 4.416 & 9.4427 & 3.716 \\
\hline & $\mathrm{EtOH}$ & 5.5960 & 4.286 & 4.2851 & 4.412 & 9.7958 & 3.670 \\
\hline & $\mathrm{MeCN}$ & 5.4953 & 4.295 & 4.3104 & 4.411 & 9.8518 & 3.697 \\
\hline
\end{tabular}

6-31G(d) ; 6-311G(d,p) ; 6-31+G(d,p) and 6-311++G(d,p) correspond, in the text, to B; B2; B1 and B3 respectively. 


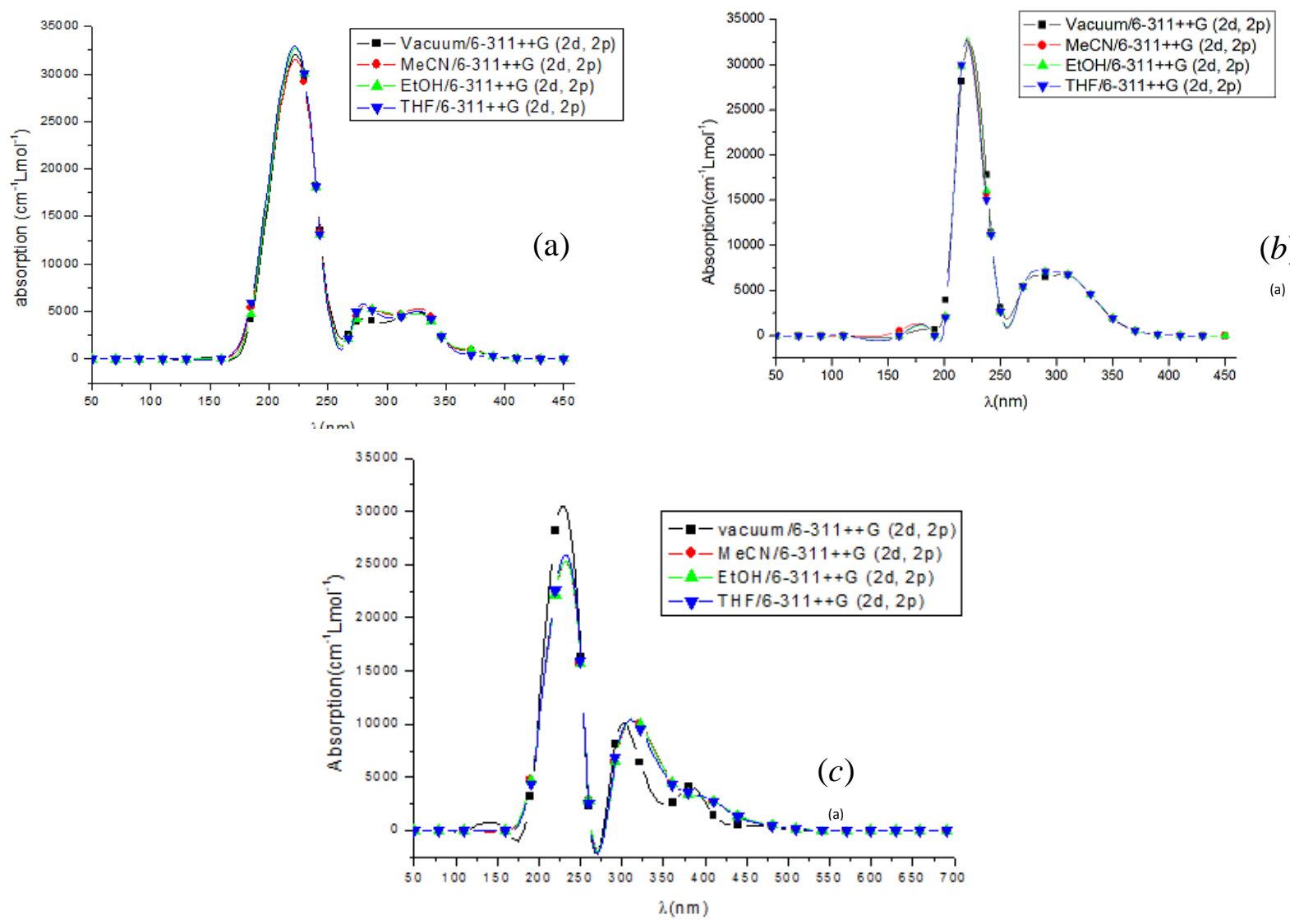

Fig. 4. Calculated electronic absorption spectra of $\mathbf{H Q}(a), \mathrm{CH}_{3} \mathbf{Q}(b)$ and $\mathbf{C H O Q}(c)$.

Table 4 summarized the results of the calculated vertical excitation energies of $\mathbf{H Q}$ in vacuum and in solution using TD-B3LYP method combined with four standard basis B, B2, B1 and B3. The comparison, between the wavelengths values, $\lambda_{\max }$ obtained in vacuum with the different basis (Table 4) and those collected from the experimental spectrum of HQ which are located about 230, 280 and 350nm, shows that both B1 and B3 basis give a better approach to the experiment with $\lambda_{\max }(222,275$ and $322 \mathrm{~nm}$ ) than that given to the basis B and B2 with $\lambda_{\max }$ values $(216,269$ and $316 \mathrm{~nm})$ and $(217,270$, and $318 \mathrm{~nm})$ respectively. Thereby, if $6-31 \mathrm{G}^{*}(\mathrm{~B})$ is sufficient to describe correctly the geometrical structure the addition of the diffuse functions in the basis seem to be necessary to better reproduce the electronic spectrum. From Table 4, the calculated vertical excitation energies of HQ using TD-B3LYP with and B and B2 are (5.74, 4.60 and 3.91) and $(5.70,4.59$ and $3.90 \mathrm{eV})$ respectively, these results were shown to be overestimated the experimental ones $(5.39,4.43$ and $3.54 \mathrm{eV})$ by $(0.35,0.17$ and 0.37 $\mathrm{eV})$ and $(0.31,0.16$ and 0.36 ) for $\mathrm{B}$ and $\mathrm{B} 2$ respectively. The calculated vertical excitation energies of HQ with TD-B3LYP combined with B1 or B3 $(5.59,4.51$ and $3.85 \mathrm{eV})$ were shown to be overestimated the experimental ones $5.39,4.43$ and $3.54 \mathrm{eV}$ by only $0.2,0.08$ and $0.31 \mathrm{eV}$ respectively. Therefore, the use of the basis containing diffuse functions improves the results and allows to obtain a better approach theory-experiment concerning the determination of the vertical excitation energies than the use of basis set without diffuse functions. In the three solvents (THF, EtOH and $\mathrm{MeCN}$ ) the results show that the better approach theory-experiment for the evaluation of vertical excitation energies is obtained using TD-B3LYP combined with B1 and B3 basis. Indeed, the use of TD-B3LYP/B3 method in THF, the evaluated vertical excitation energies are 5.60, 4.44 and $3,83 \mathrm{eV}$, the first and the third excitation energies were shown to be overestimated the experimental values by 0.21 and $0.29 \mathrm{eV}$ respectively, while a weak underestimation by 0.01 $\mathrm{eV}$ is observed for the second excitation energy. On the other hand, in $\mathrm{EtOH}$ and $\mathrm{MeCN}$, the calculated excitation energies are identical 5.60, 4.42 and 3.82 $\mathrm{eV}$, the obtained differences between the calculated excitation energies and the experimental values are the same of that evaluated in THF. Therefore, the effect of polarity solvent on the excitation energies seems to be negligible. From the above discussion, it is noteworthy that the observed overestimation of the vertical excitation energy shows that it still remains some discrepancy between theory and experiment for HQ. This discrepancy can be explained by the fact that TD-B3LYP fail to reproduce the experimentally estimated excitation energies. However, to remedy this drawback, recent research works were shown that both methods TD-LC-BLYP ${ }^{44}$ and TD-CAMB3LYP ${ }^{45}$ on the basis of the Bear's method ${ }^{46-47}$ are found to well reproduce the experimental excitation energies. 
Table 4. Energies gap $\Delta \mathrm{E}(\mathrm{eV})\left(\Delta \mathrm{E}=\mathrm{E}_{\mathrm{LUMO}}-\mathrm{E}_{\mathrm{HOMO}}\right)$, calculated absorption wavelengths $\lambda$ (nm) of $\mathbf{H Q}$ in gas phase and in solution. Only the three first transitions with an oscillator strength (f) $>0.03$ and CI expansion coefficient $>40 \%$ are reported.

\begin{tabular}{|c|c|c|c|c|c|c|}
\hline HQ & Basis set & Excitations & $\Delta \mathbf{E}(\mathbf{e V})$ & $\lambda(\mathbf{n m})$ & $\mathbf{f}$ & $\begin{array}{c}\text { CI expansion } \\
\text { coefficient }\end{array}$ \\
\hline \multirow[t]{12}{*}{ Gas } & \multirow{3}{*}{$6-31 G(d)$} & $\mathrm{HOMO} \rightarrow$ LUMO & 3.9128 & 316.87 & 0.0973 & 0.63126 \\
\hline & & HOMO-2 $\rightarrow$ LUMO & 4.6030 & 269.36 & 0.0931 & 0.61451 \\
\hline & & $\mathrm{HOMO} \rightarrow \mathrm{LUMO}+1$ & 5.7445 & 215.83 & 0.3482 & 0.50421 \\
\hline & \multirow[t]{3}{*}{ 6-311G(d,p) } & $\mathrm{HOMO} \rightarrow$ LUMO & 3.8977 & 318.09 & 0.0994 & 0.63371 \\
\hline & & HOMO-2 $\rightarrow$ LUMO & 4.5903 & 270.10 & 0.0940 & 0.61393 \\
\hline & & $\mathrm{HOMO} \rightarrow \mathrm{LUMO}+1$ & 5.7004 & 217.50 & 0.3725 & 0.49654 \\
\hline & \multirow[t]{2}{*}{$6-31+\mathrm{G}(\mathrm{d}, \mathrm{p})$} & $\mathrm{HOMO} \rightarrow$ LUMO & 3.8493 & 322.10 & 0.1040 & 0.63374 \\
\hline & & HOMO-2 $\rightarrow$ LUMO & 4.5076 & 275.06 & 0.1041 & 0.61710 \\
\hline & \multirow{4}{*}{$6-311++G(d, p)$} & $\mathrm{HOMO} \rightarrow \mathrm{LUMO}+1$ & 5.5897 & 221.81 & 0.4062 & 0.48303 \\
\hline & & $\mathrm{HOMO} \rightarrow$ LUMO & 3.8528 & 321.80 & 0.1029 & 0.63454 \\
\hline & & HOMO-2 $\rightarrow$ LUMO & 4.5120 & 274.79 & 0.1029 & 0.61743 \\
\hline & & $\mathrm{HOMO} \rightarrow \mathrm{LUMO}+1$ & 5.5879 & 221.88 & 0.3924 & 0.47960 \\
\hline \multirow[t]{12}{*}{ THF } & \multirow[t]{3}{*}{$6-31 G(d)$} & $\mathrm{HOMO} \rightarrow \mathrm{LUMO}$ & 3.8869 & 318.98 & 0.0895 & 0.62938 \\
\hline & & HOMO- $2 \rightarrow$ LUMO & 4.5244 & 274.04 & 0.1082 & 0.61811 \\
\hline & & $\mathrm{HOMO} \rightarrow \mathrm{LUMO}+1$ & 5.7597 & 215.26 & 0.3550 & 0.55460 \\
\hline & \multirow[t]{3}{*}{$6-311 G(d, p)$} & $\mathrm{HOMO} \rightarrow$ LUMO & 3.8750 & 319.96 & 0.0920 & 0.63210 \\
\hline & & HOMO- $2 \rightarrow$ LUMO & 4.5182 & 274.41 & 0.1092 & 0.61876 \\
\hline & & $\mathrm{HOMO} \rightarrow \mathrm{LUMO}+1$ & 5.7127 & 217.03 & 0.3753 & 0.54835 \\
\hline & \multirow[t]{3}{*}{$6-31+G(d, p)$} & $\mathrm{HOMO} \rightarrow$ LUMO & 3.8236 & 324.26 & 0.0949 & 0.63178 \\
\hline & & HOMO-1 $\rightarrow$ LUMO & 4.4294 & 279.91 & 0.1215 & 0.62069 \\
\hline & & $\mathrm{HOMO} \rightarrow \mathrm{LUMO}+1$ & 5.6013 & 221.35 & 0.4123 & 0.55181 \\
\hline & \multirow[t]{3}{*}{$6-311++G(d, p)$} & $\mathrm{HOMO} \rightarrow$ LUMO & 3.8264 & 324.02 & 0.0942 & 0.63271 \\
\hline & & HOMO-1 $\rightarrow$ LUMO & 4.4370 & 279.43 & 0.1194 & 0.62122 \\
\hline & & $\mathrm{HOMO} \rightarrow \mathrm{LUMO}+1$ & 5.5983 & 221.47 & 0.3960 & 0.54953 \\
\hline \multirow{12}{*}{ EtOH } & \multirow[t]{3}{*}{$6-31 \mathrm{G}(\mathrm{d})$} & HOMO $\rightarrow$ LUMO & 3.8799 & 319.56 & 0.0880 & 0.62923 \\
\hline & & HOMO-2 $\rightarrow$ LUMO & 4.5118 & 274.80 & 0.1099 & 0.61827 \\
\hline & & $\mathrm{HOMO} \rightarrow \mathrm{LUMO}+1$ & 5.7617 & 215.19 & 0.3573 & 0.56098 \\
\hline & \multirow[t]{3}{*}{$6-311 G(d, p)$} & $\mathrm{HOMO} \rightarrow$ LUMO & 3.8684 & 320.50 & 0.0906 & 0.63198 \\
\hline & & HOMO- $2 \rightarrow$ LUMO & 4.5065 & 275.13 & 0.1110 & 0.61909 \\
\hline & & $\mathrm{HOMO} \rightarrow \mathrm{LUMO}+1$ & 5.7140 & 216.98 & 0.3773 & 0.55520 \\
\hline & \multirow[t]{3}{*}{$6-31+G(d, p)$} & $\mathrm{HOMO} \rightarrow$ LUMO & 3.8164 & 324.87 & 0.0931 & 0.63166 \\
\hline & & HOMO- $1 \rightarrow$ LUMO & 4.4173 & 280.68 & 0.1234 & 0.62081 \\
\hline & & $\mathrm{HOMO} \rightarrow \mathrm{LUMO}+1$ & 5.6021 & 221.32 & 0.4153 & 0.56026 \\
\hline & \multirow[t]{3}{*}{$6-311++\mathrm{G}(\mathrm{d}, \mathrm{p})$} & $\mathrm{HOMO} \rightarrow$ LUMO & 3.8192 & 324.63 & 0.0925 & 0.63258 \\
\hline & & HOMO- $1 \rightarrow$ LUMO & 4.4252 & 280.18 & 0.1213 & 0.62137 \\
\hline & & $\mathrm{HOMO} \rightarrow \mathrm{LUMO}+1$ & 5.5991 & 221.44 & 0.3985 & 0.55812 \\
\hline \multirow[t]{12}{*}{$\mathrm{MeCN}$} & \multirow[t]{3}{*}{$6-31 G(d)$} & $\mathrm{HOMO} \rightarrow \mathrm{LUMO}$ & 3.8787 & 319.65 & 0.0878 & 0.62921 \\
\hline & & HOMO- $1 \rightarrow$ LUMO & 4.5099 & 274.92 & 0.1102 & 0.61828 \\
\hline & & $\mathrm{HOMO} \rightarrow \mathrm{LUMO}+1$ & 5.7619 & 215.18 & 0.3577 & 0.56192 \\
\hline & \multirow[t]{3}{*}{$6-311 G(d, p)$} & $\mathrm{HOMO} \rightarrow$ LUMO & 3.8673 & 320.59 & 0.0903 & 0.63197 \\
\hline & & HOMO- $2 \rightarrow$ LUMO & 4.5046 & 275.24 & 0.1112 & 0.61913 \\
\hline & & $\mathrm{HOMO} \rightarrow \mathrm{LUMO}+1$ & 5.7142 & 216.98 & 0.3777 & 0.55622 \\
\hline & \multirow[t]{3}{*}{$6-31+G(d, p)$} & $\mathrm{HOMO} \rightarrow$ LUMO & 3.8152 & 324.98 & 0.0929 & 0.63165 \\
\hline & & HOMO- $1 \rightarrow$ LUMO & 4.4154 & 280.80 & 0.1237 & 0.62082 \\
\hline & & $\mathrm{HOMO} \rightarrow \mathrm{LUMO}+1$ & 5.6022 & 221.31 & 0.4159 & 0.56150 \\
\hline & \multirow[t]{3}{*}{$6-311++G(d, p)$} & $\mathrm{HOMO} \rightarrow$ LUMO & 3.8180 & 324.73 & 0.0923 & 0.63257 \\
\hline & & HOMO-1 $\rightarrow$ LUMO & 4.4234 & 280.29 & 0.1216 & 0.62139 \\
\hline & & $\mathrm{HOMO} \rightarrow \mathrm{LUMO}+1$ & 5.5992 & 221.43 & 0.3990 & 0.55936 \\
\hline
\end{tabular}

6-31G(d); 6-311G(d,p) ; 6-31+G(d,p) and 6-311++G(d,p) correspond, in the text, to B; B2; B1 and B3 respectively. 
Table 5. Energies gap $\Delta \mathrm{E}(\mathrm{eV})\left(\Delta \mathrm{E}=\mathrm{E}_{\mathrm{LumO}}-\mathrm{E}_{\mathrm{HOMO}}\right)$, calculated absorption wavelengths $\lambda(\mathrm{nm})$ of $\mathbf{C H}_{\mathbf{3}} \mathbf{Q}$ in gas phase and in solution. Only the three first transitions with an oscillator strength (f) $>0.1$ and CI expansion coefficient $>48 \%$ are reported.

\begin{tabular}{|c|c|c|c|c|c|c|}
\hline $\mathrm{CH}_{3} \mathrm{Q}$ & Basis set & Excitations & $\Delta \mathrm{E}(\mathrm{eV})$ & $\lambda(\mathrm{nm})$ & $\mathbf{f}$ & $\begin{array}{c}\text { CI expansion } \\
\text { coefficient }\end{array}$ \\
\hline \multirow[t]{13}{*}{ Gas } & \multirow[t]{3}{*}{$6-31 G(d)$} & $\mathrm{HOMO} \rightarrow \mathrm{LUMO}$ & 4.0235 & 308.15 & 0.1345 & 0.62656 \\
\hline & & HOMO-2 $\rightarrow$ LUMO & 4.6288 & 267.85 & 0.1129 & 0.61474 \\
\hline & & $\mathrm{HOMO} \rightarrow \mathrm{LUMO}+1$ & 5.6978 & 217.60 & 0.2688 & 0.50786 \\
\hline & \multirow[t]{3}{*}{$6-311 \mathrm{G}(\mathrm{d}, \mathrm{p})$} & HOMO-1 $\rightarrow$ LUMO & 4.0185 & 308.54 & 0.1399 & 0.62873 \\
\hline & & HOMO- $\rightarrow$ LUMO & 4.6197 & 268.38 & 0.1137 & 0.61415 \\
\hline & & HOMO $\rightarrow$ LUMO+1 & 5.6521 & 219.36 & 0.2803 & 0.50005 \\
\hline & \multirow[t]{3}{*}{$6-31+G(d, p)$} & \multirow{3}{*}{$\begin{array}{l}\mathrm{HOMO} \rightarrow \text { LUMO } \\
\mathrm{HOMO}-2 \rightarrow \text { LUMO } \\
\mathrm{HOMO} \rightarrow \text { LUMO+1 }\end{array}$} & 3.9670 & 312.54 & 0.1486 & 0.62823 \\
\hline & & & 4.5357 & 273.35 & 0.1225 & 0.61748 \\
\hline & & & 5.5485 & 223.46 & 0.2946 & 0.48383 \\
\hline & \multirow[t]{4}{*}{$6-311++G(d, p)$} & \multirow{4}{*}{$\begin{array}{l}\mathrm{HOMO} \rightarrow \text { LUMO } \\
\text { HOMO-2 } \rightarrow \text { LUMO } \\
\text { HOMO } \rightarrow \text { LUMO+1 }\end{array}$} & 3.9741 & 311.98 & 0.1470 & 0.62916 \\
\hline & & & 4.5420 & 272.97 & 0.1207 & 0.61786 \\
\hline & & & 5.5438 & 223.65 & 0.2802 & 0.48030 \\
\hline & & & & & & \\
\hline \multirow[t]{13}{*}{ THF } & \multirow[t]{3}{*}{$6-31 G(d)$} & $\mathrm{HOMO} \rightarrow \mathrm{LUMO}$ & 4.0046 & 309.61 & 0.1262 & 0.62503 \\
\hline & & HOMO-2 $\rightarrow$ LUMO & 4.5630 & 271.72 & 0.1236 & 0.61922 \\
\hline & & $\mathrm{HOMO} \rightarrow \mathrm{LUMO}+1$ & 5.7067 & 217.26 & 0.2683 & 0.55110 \\
\hline & \multirow[t]{3}{*}{ 6-311G(d,p) } & $\mathrm{HOMO} \rightarrow \mathrm{LUMO}$ & 4.0027 & 309.75 & 0.1323 & 0.62760 \\
\hline & & HOMO-2 $\rightarrow$ LUMO & 4.5633 & 271.70 & 0.1237 & 0.61961 \\
\hline & & $\mathrm{HOMO} \rightarrow \mathrm{LUMO}+1$ & 5.6591 & 219.09 & 0.2782 & 0.54260 \\
\hline & \multirow[t]{3}{*}{$6-31+G(d, p)$} & HOMO $\rightarrow$ LUMO & 3.9502 & 313.87 & 0.1394 & 0.62654 \\
\hline & & HOMO- $1 \rightarrow$ LUMO & 4.4726 & 277.21 & 0.1345 & 0.62192 \\
\hline & & $\mathrm{HOMO} \rightarrow \mathrm{LUMO}+1$ & 5.5587 & 223.04 & 0.2934 & 0.54250 \\
\hline & \multirow{4}{*}{$6-311++G(d, p)$} & & 3.9572 & 313.31 & 0.1384 & 0.62762 \\
\hline & & $\mathrm{HOMO} \rightarrow$ LUMO & 4.4823 & 276.61 & 0.1321 & 0.62251 \\
\hline & & HOMO-1 $\rightarrow$ LUMO & 5.5530 & 223.27 & 0.2779 & 0.54054 \\
\hline & & $\mathrm{HOMO} \rightarrow \mathrm{LUMO}+1$ & & & & \\
\hline \multirow[t]{13}{*}{ EtOH } & \multirow[t]{3}{*}{$6-31 G(d)$} & $\mathrm{HOMO} \rightarrow \mathrm{LUMO}$ & 3.9995 & 310.00 & 0.1246 & 0.62498 \\
\hline & & HOMO-1 $\rightarrow$ LUMO & 4.5527 & 272.33 & 0.1248 & 0.61960 \\
\hline & & $\mathrm{HOMO} \rightarrow \mathrm{LUMO}+1$ & 5.7080 & 217.21 & 0.2696 & 0.55688 \\
\hline & \multirow[t]{3}{*}{$6-311 G(d, p)$} & $\mathrm{HOMO} \rightarrow \mathrm{LUMO}$ & 3.9982 & 310.10 & 0.1308 & 0.62761 \\
\hline & & HOMO- $\rightarrow$ LUMO & 4.5546 & 272.22 & 0.1248 & 0.62014 \\
\hline & & $\mathrm{HOMO} \rightarrow \mathrm{LUMO}+1$ & 5.6601 & 219.05 & 0.2797 & 0.54848 \\
\hline & \multirow[t]{3}{*}{$6-31+G(d, p)$} & $\mathrm{HOMO} \rightarrow \mathrm{LUMO}$ & 3.9457 & 314.22 & 0.1376 & 0.62647 \\
\hline & & HOMO- $1 \rightarrow$ LUMO & 4.4631 & 277.80 & 0.1359 & 0.62225 \\
\hline & & $\mathrm{HOMO} \rightarrow$ LUMO +1 & 5.5600 & 222.99 & 0.2954 & 0.55036 \\
\hline & \multirow[t]{4}{*}{$6-311++G(d, p)$} & & 3.9527 & 313.67 & 0.1367 & 0.62755 \\
\hline & & HOMO $\rightarrow$ LUMO & 4.4731 & 277.18 & 0.1334 & 0.62288 \\
\hline & & HOMO-1 $\rightarrow$ LUMO & 5.5542 & 223.23 & 0.2798 & 0.54851 \\
\hline & & HOMO $\rightarrow$ LUMO+1 & & & & \\
\hline \multirow[t]{13}{*}{$\mathrm{MeCN}$} & \multirow[t]{3}{*}{$6-31 G(d)$} & $: \mathrm{HOMO} \rightarrow \mathrm{LUMO}$ & 3.9987 & 310.06 & 0.1243 & 0.62498 \\
\hline & & HOMO-1 $\rightarrow$ LUMO & 4.5512 & 272.42 & 0.1250 & 0.61966 \\
\hline & & $\mathrm{HOMO} \rightarrow \mathrm{LUMO}+1$ & 5.7081 & 217.21 & 0.2699 & 0.55775 \\
\hline & $6-311 G(d, p)$ & $\mathrm{HOMO} \rightarrow \mathrm{LUMO}$ & 3.9975 & 310.16 & 0.1306 & 0.62762 \\
\hline & & HOMO-2 $\rightarrow$ LUMO & 4.5532 & 272.30 & 0.1249 & 0.61954 \\
\hline & & HOMO $\rightarrow$ LUMO+1 & 5.6602 & 219.05 & 0.2800 & 0.54937 \\
\hline & $6-31+G(d, p)$ & $\mathrm{HOMO} \rightarrow \mathrm{LUMO}$ & 3.9450 & 314.28 & 0.1373 & 0.62646 \\
\hline & & HOMO- $1 \rightarrow$ LUMO & 4.4616 & 277.89 & 0.1361 & 0.62230 \\
\hline & & $\mathrm{HOMO} \rightarrow \mathrm{LUMO}+1$ & 5.5602 & 222.99 & 0.2958 & 0.55154 \\
\hline & $6-311++G(d, p)$ & & 3.9520 & 313.73 & 0.1364 & 0.62755 \\
\hline & & $\mathrm{HOMO} \rightarrow$ LUMO & 4.4717 & 277.26 & 0.1336 & 0.62293 \\
\hline & & HOMO-1 $\rightarrow$ LUMO & 5.5544 & 223.22 & 0.2801 & 0.54970 \\
\hline & & $\mathrm{HOMO} \rightarrow \mathrm{LUMO}+1$ & & & & \\
\hline
\end{tabular}

6-31G(d) ; 6-311G(d,p) ; 6-31+G(d,p) and 6-311++G(d,p) correspond, in the text, to B; B2; B1 and B3 respectively. 
Table 6. Energies gap $\Delta \mathrm{E}(\mathrm{eV})\left(\Delta \mathrm{E}=\mathrm{E}_{\mathrm{LUMO}}-\mathrm{E}_{\mathrm{HOMO}}\right)$, calculated absorption wavelengths $\lambda(\mathrm{nm})$ of $\mathbf{C H O Q}$ in gas phase and in solution. Only the three first transitions with an oscillator strength (f) $>0.1$ and $\mathrm{CI}$ expansion coefficient $>40 \%$ are reported.

\begin{tabular}{|c|c|c|c|c|c|c|}
\hline CHOQ & Basis set & Excitations & $\Delta \mathrm{E}(\mathrm{eV})$ & $\lambda(\mathbf{n m})$ & $\mathbf{f}$ & $\begin{array}{l}\text { CI expansion } \\
\text { coefficient }\end{array}$ \\
\hline \multirow[t]{12}{*}{ Gas } & \multirow[t]{3}{*}{$6-31 G(d)$} & HOMO-1 $\rightarrow$ LUMO & 3.3151 & 374.00 & 0.0972 & 0.64033 \\
\hline & & HOMO- $2 \rightarrow$ LUMO & 4.1941 & 295.62 & 0.2087 & 0.61939 \\
\hline & & $\mathrm{HOMO}-1 \rightarrow \mathrm{LUMO}+2$ & 5.3240 & 232.88 & 0.0573 & 0.41602 \\
\hline & \multirow[t]{3}{*}{$6-311 G(d, p)$} & HOMO-1 $\rightarrow$ LUMO & 3.3318 & 372.12 & 0.0997 & 0.64222 \\
\hline & & HOMO-2 $\rightarrow$ LUMO & 4.2016 & 295.09 & 0.2095 & 0.62067 \\
\hline & & $\mathrm{HOMO}-1 \rightarrow \mathrm{LUMO}+2$ & 5.2810 & 234.77 & 0.0535 & 0.43936 \\
\hline & \multirow[t]{3}{*}{$6-31+G(d, p)$} & $\mathrm{HOMO} \rightarrow \mathrm{LUMO}$ & 3.2754 & 378.53 & 0.1016 & 0.64236 \\
\hline & & HOMO- $2 \rightarrow$ LUMO & 4.1211 & 300.85 & 0.2272 & 0.62177 \\
\hline & & $\mathrm{HOMO} \rightarrow \mathrm{LUMO}+2$ & 5.1848 & 239.13 & 0.0600 & 0.43350 \\
\hline & \multirow{3}{*}{$6-311++G(d, p)$} & $\mathrm{HOMO} \rightarrow \mathrm{LUMO}$ & 3.2974 & 376.00 & 0.1016 & 0.64298 \\
\hline & & HOMO- $2 \rightarrow$ LUMO & 4.1396 & 299.51 & 0.2246 & 0.62214 \\
\hline & & $\mathrm{HOMO} \rightarrow \mathrm{LUMO}+2$ & 5.1852 & 239.11 & 0.0476 & 0.46211 \\
\hline \multirow[t]{12}{*}{ THF } & \multirow[t]{3}{*}{$6-31 G(d)$} & $\mathrm{HOMO} \rightarrow \mathrm{LUMO}$ & 3.2206 & 384.97 & 0.0796 & 0.64080 \\
\hline & & HOMO- $2 \rightarrow$ LUMO & 4.0647 & 305.03 & 0.2400 & 0.61746 \\
\hline & & $\mathrm{HOMO} \rightarrow \mathrm{LUMO}+1$ & 5.3351 & 232.39 & 0.0599 & 0.39071 \\
\hline & \multirow{3}{*}{$6-311 G(d, p)$} & $\mathrm{HOMO} \rightarrow$ LUMO & 3.2403 & 382.64 & 0.0822 & 0.64261 \\
\hline & & HOMO-2 $\rightarrow$ LUMO & 4.0763 & 304.16 & 0.2410 & 0.61937 \\
\hline & & $\mathrm{HOMO} \rightarrow \mathrm{LUMO}+1$ & 5.3088 & 233.54 & 0.0591 & 0.39971 \\
\hline & \multirow[t]{3}{*}{$6-31+\mathrm{G}(\mathrm{d}, \mathrm{p})$} & HOMO $\rightarrow$ LUMO & 3.1830 & 389.52 & 0.0812 & 0.64315 \\
\hline & & HOMO-2 $\rightarrow$ LUMO & 3.9908 & 310.68 & 0.2628 & 0.61926 \\
\hline & & $\mathrm{HOMO} \rightarrow \mathrm{LUMO}+1$ & 5.2131 & 237.83 & 0.1087 & 0.47714 \\
\hline & \multirow[t]{3}{*}{$6-311++G(d, p)$} & $\mathrm{HOMO} \rightarrow$ LUMO & 3.2043 & 386.93 & 0.0819 & 0.64356 \\
\hline & & HOMO-2 $\rightarrow$ LUMO & 4.0120 & 309.03 & 0.2587 & 0.61983 \\
\hline & & $\mathrm{HOMO} \rightarrow \mathrm{LUMO}+1$ & 5.2240 & 237.33 & 0.0978 & 0.45988 \\
\hline \multirow[t]{12}{*}{ EtOH } & \multirow[t]{3}{*}{$6-31 G(d)$} & $\mathrm{HOMO} \rightarrow \mathrm{LUMO}$ & 3.2016 & 387.25 & 0.0765 & 0.64101 \\
\hline & & HOMO- $2 \rightarrow$ LUMO & 4.0435 & 306.63 & 0.2447 & 0.61685 \\
\hline & & $\mathrm{HOMO} \rightarrow \mathrm{LUMO}+1$ & 5.3301 & 232.61 & 0.0654 & 0.40598 \\
\hline & \multirow{3}{*}{$6-311 G(d, p)$} & $\mathrm{HOMO} \rightarrow \mathrm{LUMO}$ & 3.2222 & 384.78 & 0.0791 & 0.64279 \\
\hline & & HOMO- $2 \rightarrow$ LUMO & 4.0557 & 305.71 & 0.2458 & 0.61882 \\
\hline & & $\mathrm{HOMO} \rightarrow \mathrm{LUMO}+1$ & 5.3073 & 233.61 & 0.0668 & 0.41867 \\
\hline & \multirow{3}{*}{$6-31+\mathrm{G}(\mathrm{d}, \mathrm{p})$} & $\mathrm{HOMO} \rightarrow$ LUMO & 3.1640 & 391.86 & 0.0776 & 0.64342 \\
\hline & & HOMO $-2 \rightarrow$ LUMO & 3.9699 & 312.31 & 0.2678 & 0.61855 \\
\hline & & $\mathrm{HOMO} \rightarrow \mathrm{LUMO}+1$ & 5.2041 & 238.24 & 0.1368 & 0.51984 \\
\hline & \multirow{3}{*}{$6-311++G(d, p)$} & $\mathrm{HOMO} \rightarrow$ LUMO & 3.1858 & 389.18 & 0.0784 & 0.64378 \\
\hline & & HOMO- $-\rightarrow$ LUMO & 3.9916 & 310.61 & 0.2636 & 0.61913 \\
\hline & & $\mathrm{HOMO} \rightarrow \mathrm{LUMO}+1$ & 5.2165 & 237.68 & 0.1339 & 0.51701 \\
\hline \multirow[t]{12}{*}{$\mathrm{MeCN}$} & \multirow[t]{3}{*}{$6-31 G(d)$} & $\mathrm{HOMO} \rightarrow$ LUMO & 3.1986 & 387.63 & 0.0760 & 0.64105 \\
\hline & & HOMO-2 $\rightarrow$ LUMO & 4.0402 & 306.88 & 0.2454 & 0.61676 \\
\hline & & $\mathrm{HOMO} \rightarrow \mathrm{LUMO}+1$ & 5.3291 & 232.65 & 0.0666 & 0.40897 \\
\hline & \multirow{3}{*}{$6-311 G(d, p)$} & $\mathrm{HOMO} \rightarrow \mathrm{LUMO}$ & 3.2193 & 385.13 & 0.0786 & 0.64282 \\
\hline & & HOMO-2 $\rightarrow$ LUMO & 4.0524 & 305.95 & 0.2465 & 0.61873 \\
\hline & & $\mathrm{HOMO} \rightarrow \mathrm{LUMO}+1$ & 5.3068 & 233.63 & 0.0683 & 0.42227 \\
\hline & \multirow[t]{3}{*}{$6-31+\mathrm{G}(\mathrm{d}, \mathrm{p})$} & $\mathrm{HOMO} \rightarrow$ LUMO & 3.1609 & 392.25 & 0.0770 & 0.64347 \\
\hline & & HOMO- $2 \rightarrow$ LUMO & 3.9667 & 312.57 & 0.2686 & 0.61844 \\
\hline & & $\mathrm{HOMO} \rightarrow \mathrm{LUMO}+1$ & 5.2021 & 238.33 & 0.1415 & 0.52650 \\
\hline & \multirow{3}{*}{$6-311++\mathrm{G}(\mathrm{d}, \mathrm{p})$} & $\mathrm{HOMO} \rightarrow$ LUMO & 3.1828 & 389.55 & 0.0778 & 0.64383 \\
\hline & & HOMO- $2 \rightarrow$ LUMO & 3.9884 & 310.86 & 0.2643 & 0.61902 \\
\hline & & $\mathrm{HOMO} \rightarrow \mathrm{LUMO}+1$ & 5.2146 & 237.76 & 0.1399 & 0.52564 \\
\hline
\end{tabular}

6-31G(d) ; 6-311G(d,p) ; 6-31+G(d,p) and 6-311++G(d,p) correspond, in the text, to B; B2; B1 and B3 respectively. 
For the quinoxaline derivatives, the extension of the basis set produce a slight bathochromic shifts estimated by 5 to $6 \mathrm{~nm}$ as difference between the $\lambda_{\max }$ calculated using the less and the most extended basis (6-31G(d) (B) and 6-311++G(d,p) (B3)) in vacuum and in the three polar solvents considered in this work. To sum up, the theoretical calculations of the electronic spectrum with extended basis 6-311++G (d,p) containing-diffuse orbitals gave results in better agreement with the experiment.

A hypochromic shift is clearly noticed on the UV spectrum of the CHOQ compound for the absorption band intensity at $237.7 \mathrm{~nm}$ (using B3 in EtOH), this shift is the most important compared to the two other peaks at 310.6 and $389.2 \mathrm{~nm}$ (see Fig. 4 and Table 6). While a slight hypochromic shift appears on the two absorption bands at larger wavelengths $\lambda_{\max }$ for $\mathbf{H Q}$ and $\mathbf{C H}_{\mathbf{3}} \mathbf{Q}$ (Fig. 4, Tables 4 and 5). There is almost no effect of the solvent on the most intense peak centered at the shortest one (221.8 and $223.7 \mathrm{~nm}$ for $\mathbf{H Q}$ and $\mathbf{C H}_{\mathbf{3}} \mathbf{Q}$ respectively).

A bathochromic shift on the two larger absorption bands due to the solvent effect is noticed for the studied compounds. This shift is more important for CHOQ and increase with the solvent polarity for the three quinoxaline derivatives. Moreover, one can notice weak hypsochromic shifts in the shorter wavelength $\left(\lambda_{\max }\right)$ (See Tables 4-6). Considering the results obtained using B3 in the vacuum and in $\mathrm{MeCN}$ solvent which is the most polar of the three solvents used in this work since its dielectric constant is higher than those of $\mathrm{EtOH}$ and THF. Therefore, it is possible to evaluate the bathochromic or hypsochromic shifts due to the solvent as a difference between the wavelength values $\left(\lambda_{\max }\right)$ in the vacuum and in the presence of the solvent. For bathochromic shifts, this difference is estimated for the tow larger values of $\lambda_{\max }$ at 3 and $6 \mathrm{~nm}, 2$ and $4 \mathrm{~nm}$ and 13.6 and $11.4 \mathrm{~nm}$ for $\mathbf{H Q}$, $\mathbf{C H}_{3} \mathbf{Q}$ and $\mathbf{C H O Q}$ respectively, while the hypsochromic shift is evaluated by $0.4 \mathrm{~nm}$ for $\mathbf{H Q}$ and $\mathbf{C H}_{3} \mathbf{Q}$ molecules and $1.3 \mathrm{~nm}$ for $\mathbf{C H O Q}$ molecule. In many aspects, an obvious effect of the solvent polarity on the electronic spectra of the studied compound is highlighted especially for CHOQ compound.

For HQ the three first absorption peaks at 324.6, 280.2 and $221.4 \mathrm{~nm}$ obtained with B31YP/B3 in EtOH (Table 4 and Fig. 4(a)) are in good agreement with the experimental UV spectrum given in Fig.1 which shows absorption bands at 350, 280 and 230 $\mathrm{nm}$ respectively. However, the difference between the theoretical and experimental $\lambda_{\max }$ values for the absorption bands at 324.6 and 221.4 are 15 and $8 \mathrm{~nm}$ respectively less than $20 \mathrm{~nm}$ obtained by $\mathrm{N}$. Prabavathi et al. ${ }^{48}$. The long-wavelength absorption transition at $324.6 \mathrm{~nm}$ could be assigned to the $\mathrm{HOMO} \rightarrow$ LUMO transition (contribution of $63 \%$, Table 4). The HOMO has a pronounced $\pi$ character localized on the quinoxaline moiety and on the oxygen atom of the carboxyl group of HQ, whereas the LUMO has antibonding $\pi$ character (Fig. 3). The $\mathrm{HOMO} \rightarrow$ LUMO transition is then characterized as a $\pi \rightarrow \pi^{*}$ electronic transition. The calculated absorption band at $280.2 \mathrm{~nm}$ could be attributed to HOMO-1 $\rightarrow$ LUMO transition with a contribution of $62 \%$ (Table 4). The isodensity surface plots of the molecular orbitals (MOs) (Fig. 3) show that the HOMO-1 has a $\pi$ character on the benzene ring, thus, this band is assigned also to $\pi \rightarrow \pi^{*}$ transition.

In the theoretical electronic spectrum of $\mathbf{C H}_{3} \mathbf{Q}$ molecule obtained in EtOH and with 6-311++G(d,p) (B3) as a basis set, the absorption bands appear at 313.7, 277.2 and 223.2 nm (Table 5 and Fig. 4 (b)). The absorption peak at $313.67 \mathrm{~nm}$ could probably be attributed to $\mathrm{HOMO} \rightarrow$ LUMO excitation with a contribution of $0.63 \%$, The HOMO has a pronounced $\pi$ character localized on $\pi$-system of quinoxaline moiety while the LUMO has antibonding $\pi$ character mostly localized on the quinoxaline moiety (Fig. 3); therefore, this excitation is attributed to $\pi-\pi^{*}$ transition. The absorption peak at $277.2 \mathrm{~nm}$ involves the HOMO-1 $\rightarrow$ LUMO excitation with a contribution of $62 \%$, the isodensity plots of the HOMO-1 (Fig. 3) shows a pronounced $\pi$-character on the benzene, this electronic excitation is assigned to $\pi-\pi^{*}$ transition mainly localized on the benzene ring. The last wavelength at $223.2 \mathrm{~nm}$ corresponds to the $\mathrm{HOMO} \rightarrow \mathrm{LUMO}+1$ excitation with $55 \%$ as a contribution in the IC function, moreover, LUMO+1 present a pronounced antibonding character with a high electronic density on the $\pi$-system of the benzene, as a consequence this excitation is assigned to $\pi-\pi^{*}$ transition.

Table 6 and Fig. 4 (c), show three $\lambda_{\max }$ values calculated at 389.2, 310.6 and $237.7 \mathrm{~nm}$ for CHOQ derivative, the major IC coefficients show that these peaks can correspond to HOMO $\rightarrow$ LUMO, HOMO$2 \rightarrow$ LUMO and $\mathrm{HOMO} \rightarrow$ LUMO+1 excitations respectively. The electronic density (Fig. 3) allows to deduce that these excitations are assigned to $\pi-\pi^{*}$ transition since the HOMO present a high density on the quinoxaline ring, the HOMO-2 is localized on $\mathrm{N}$ atomic centers and on the benzene ring. The LUMO and LUMO+1 present an anti-bonding $\pi$ character localized on the quinoxaline ring and on benzene ring respectively. To conclude, the three calculated absorption bands are mainly derived from the contribution of excitations due to $\pi-\pi^{*}$ transition.

The comparison between $\mathbf{H Q}$ and $\mathbf{C H}_{\mathbf{3}} \mathbf{Q}$ results (Tables 4-5) shows an undergo hypsochromic shifts on the three absorption bands. For the theoretical band calculated at 321.8 and $324.6 \mathrm{~nm}$ for $\mathbf{H Q}$ in a vacuum and EtOH and using 6-311++G (d, p) basis, this shift is evaluated by 10 and $11 \mathrm{~nm}$ in vacuum and in EtOH respectively. For two other peaks, calculated in EtOH and using 6-311++G (d,p), at 280.2 and $221.4 \mathrm{~nm}$, this hypsochromic shifts is 
weak and estimated to 3 and $2 \mathrm{~nm}$ respectively. A bathochromic shift caused by the substitution of the $\mathrm{H}$ in $\mathbf{H Q}$ by $\mathrm{CHO}$ group is deduced from the results given in Tables 6 and Fig. 4. In EtOH and using 6$311++\mathrm{G}(\mathrm{d}, \mathrm{p})$, this shift is strong and estimated to 65 $\mathrm{nm}$ for the peak at 324.6, while it is evaluated by 30 and $16 \mathrm{~nm}$ for the absorption bands at 280.2 and $221.4 \mathrm{~nm}$ respectively. One can notice a hypochromic effect on the three band intensities due to the substitution of $\mathrm{H}$ in $\mathbf{H Q}$ by $\mathrm{CH}_{3}$; while a hyperchromic effect is observed on the three peaks when one replace $\mathrm{H}$ in $\mathbf{H Q}$ by $\mathrm{CHO}$ group.

\section{Conclusion}

The geometrically optimized structures of HQ, $\mathrm{CH}_{3} \mathbf{Q}$ and $\mathrm{CHOQ}$ show that the bond distances and bond angles related to quinoxaline rings are in good agreement with the experiment. The use $6-31 G^{*}$ is sufficient to well describe the geometrical structure of quinoxaline derivatives. However, the addition of the diffuse functions in the basis is necessary to improve the theory-experiment approach concerning the evaluation of the excitation energies.

The most important energetic stabilization caused by the solvent polarity is observed for CHOQ compound.

The calculated excitation energies using TD-B3LYP underestimate or overestimate the experimental values, therefore this method fail to reproduce the experimentally estimated excitation energies.

The most bathochromic and hypsochromic shifts on the $\lambda_{\max }$ values are clearly observed for CHOQ compound, in the UV spectrum, due to the strong effect of solvent polarity. Indeed, the bathochromic effect is observed for the two larger $\lambda_{\max }$ values and the major hypsochromic effect is noticed for the shorter wavelength value of $\lambda_{\max }$.

The calculated UV absorption maxima at 324.6, 280.2 and $221.4 \mathrm{~nm}$, obtained for HQ using extended basis sets containing diffuse orbitals in $\mathrm{EtOH}$ as the solvent, is in good agreement with the experiment. The three absorption bands are derived from the contribution of the excitations due to $\pi-\pi^{*}$ transitions. From the electronics spectra of HQ, $\mathbf{C H}_{3} \mathbf{Q}$ and $\mathbf{C H O Q}$, one can deduce that the substitution of $\mathrm{H}$ in HQ by $\mathrm{CH}_{3}$ group (electrodonor) cause an undergo hypsochromic shift on $\lambda_{\max }$ values. While the substitution of $\mathrm{H}$ by $\mathrm{CHO}$ (electroattractor) occurs a bathochromic shift in wavelength associated to the absorption maximum. A hypochromic and hyperchromic effects are clearly noticed on the absorption band when we replace $\mathrm{H}$ in HQ by $\mathrm{CH}_{3}$ and $\mathrm{CHO}$ group respectively. Thus it is possible to establish a direct relationship between the nature of substituent group (electro-donor/attractor) and the different effects on the displacement and intensity of the absorption bands observed in the UV spectra of quinoxaline derivatives.

\section{References}

1- V. Krishnakumar, N. Prabavathi, Spectrochim. Acta, Part A, 2010, 77, 238-247.

2- H. Kinashi, S.L. Otten, J.S. Duncan, C.R. Hutchinson, J. Antibiot., 1988, 41 624-637.

3- R. Sarges, H.R. Howard, R.G. Browne, L.A. Lebel, P.A. Seymour, B.K. Koe, J. Med. Chem., 1990, 33, 2240-2254.

4- W. Losher, H. Lehmann, B. Behl, W. Lubish, T. Hoger, H.G. Lemair, G. Gross, Eur.

J. Neurosci., 1999, 11, 250-262.

5- P. Sanna, A. Carta, M. Loriga, S. Zanetti, L. Sechi, II Farmaco, 1998, 53, 455-461.

6- Y.B. Kim, Y.H. Kim, J.Y. Park, S.K. Kim, Bioorg. Med. Chem. Lett., 2004, 14, 541-544.

7- S.T. Hazeldine, L. Polin, J. Kushner, K. White, T.H. Corbett, J. Biehl, J.P. Horwitz, Bioorg. Med. Chem., 2005, 13, 1069-1081.

8- S.T. Hazeldine, L. Polin, J. Kushner, K. White, T.H. Corbett, J. Biehl, J.P. Horwitz, Bioorg. Med. Chem., (2005), 13, 3910-3920.

9- S.T. Hazeldine, L. Polin, J. Kushner, K. White, N.M. Bouregeois, B. Crantz, E. Palomino, T.H. Corbett, J. Biehl, J.P. Horwitz, Bioorg. Med. Chem., 2002, 45 3130-3137.

10- S.T. Hazeldine, L. Polin, J. Kushner, J. Paluch, K. White, M. Edelstein, E. Palomino, T.H. Corbett, J.P. Horwitz, Bioorg. Med. Chem., 2001, 44, 1758-1776.

11- Y. Ikeda, E. Kuwano, M. Eto, J. Fac. Agric., 1992, 37, 81-92.

12- Y. Ura, G. Sakata, K. Makino, T. Ikai, Y. Kawamura, German Offenlegungschrift DE, 3004770 .

13- N.T. Ghomsi, N.H. Ahabchane, N. Es-Safi, B. Garrigues, E.M. Essasi, Spectrosc. Lett., 2007, 40, 741-751.

14- D. Rose, E. Liesk, H. Hoeffkes, K.-G. A. Hengel, German Offenlegungschrift DE, 1999, 3, 212.

15- K. Toshima, R. Takano, T. Ozawa, S. Matsumura, J. Chem. Soc. Chem. Commun., 2002, 212-213. DOI: 10.1039/B107829C.

16- G. Ughetto, A.H.J. Wang, G.J. Quigley, G.A. Van Der Marel, J.H. Van Boom, A. Rich, Nucleic Acids Res., 1985, 13, 2305-2323.

17- M.A. Viswamitra, O. Kennard, W.B.T. Cruse, E. Egert, G.M. Sheldrick, P.G. Jones, M.J. Waring, L.P.G. Wakelin, R.K. Olsen, Nature (London), 1981, 289, 817.

18- M.A. Palafox, G. Tardajos, A.G. Martines, V.K. Rastogi, D. Mishra, S.P. Ojha, W. Kiefer, Chem. Phys., 2007, 340, 17-31.

19- N.C. Handy, P.E. Masley, R.D. Amos, J.S. Andrews, C.W. Murray, G. Laming, Chem. Phys. Lett., 1992, 197, 506-515.

20- N.C. Handy, C.W. Murray, R.D. Amos, J. Phys. Chem., 1993, 97, 4392-4396.

21- P.J. Stephens, F.J. Devlin, C.F. Chavalowski, M.J. Frisch, J. Phys. Chem., 1994, 98, 11623-11627. 
22- F.J. Devlin, J.W. Finley, P.J. Stephens, M.J. Frisch, J. Phys. Chem., 1995, 99, 16883-16902.

23- J.-P. Cornard, C. Lapouge, Chem. Phys. Lett., 2007, 438, 41-47.

24- J.-P. Cornard, C. Lapouge, J.-C. Merlin, Chem. Phys., 2007, 340, 273-282.

25- Ş. Yurdakul, T. Polat, J. Mol. Struct., 2010, 963, 194-201.

26- N. Padjama, S. Ramakumar, M.A. Viswamitra, Acta Cryst. C, 1987, 43, 2239-2240.

27- N. Prabavathi, A. Nilufer, V. Krishnakumar, Spectrochim. Acta, Part A, 2012, 92, 325- 335.

28- S.M. Soliman, J. Albering, M.A.M. AbuYoussef, J. Mol. Struct., 2013, 1053, 48-60.

29- S. Badoğlu, Ş. Yurdakul, Spectrochim. Acta, Part A, 2013, 101, 14-21.

30- Rajratna P. Tayade, Nagaiyan Sekar, J. Lumin., 2016, 176, 298-308.

31- S. Sebastian, S. Sylvestre, J. Jayabharathi, S. Ayyapan, M. Amalanathan, K. Oudayakumar, Ignatius A. Herman, Spectrochimica Acta Part A, 2015, 136, 1107-1118.

32- Y. S. Hong, H. M. Kim, Y.T. Park, H. S. Kim, Bull. Korean Chem. Soc., 2000, 21, 133-136.

33- A.D. Becke, J. Chem. Phys., 1992, 96, 94899495.

34- A.D. Becke, J. Chem. Phys., 1993, 98, 1372-1377.

35- C. Lee, W. Yang, R.G. Parr, Phys. Rev. B, 1988, 37, 785-789.

36- M.J. Frisch, G.W. Trucks, H.B. Schlegel, G.E. Scuseria, M.A. Robb, J.R. Cheeseman, J.A. Montgomery, Jr., T. Vreven, K.N. Kudin, J.C. Burant, J.M. Millam, S.S. Iyengar, J. Tomasi, V. Barone, B. Mennucci, M. Cossi, G. Scalmani, N. Rega, G.A. Petersson, H. Nakatsuji, M. Hada, M. Ehara, K. Toyota, R. Fukuda, J. Hasegawa, M. Ishida, T. Nakajima, Y. Honda, O. Kitao, H. Nakai, M. Klene, X. Li, J.E. Knox, H.P. Hratchian, J.B. Cross, C. Adamo, J. Jaramillo, R. Gomperts, R.E. Stratmann, O. Yazyev, A.J. Austin, R. Cammi, C. Pomelli, J.W. Ochterski, P.Y. Ayala, K.
Morokuma, G.A. Voth, P. Salvador, J.J. Dannenberg, V.G. Zakrzewski, S. Dapprich, A.D. Daniels, M.C. Strain, O. Farkas, D.K. Malick, A.D. Rabuck, K. Raghavachari, J.B. Foresman, J.V. Ortiz, Q. Cui, A.G. Baboul, S. Clifford, J. Cioslowski, B.B. Stefanov, G. Liu, A. Liashenko, P. Piskorz, I. Komaromi, R.L. Martin, D.J. Fox, T. Keith, M.A. Al-Laham, C.Y. Peng, A. Nanayakkara, M. Challacombe, P.M.W. Gill, B. Johnson, W. Chen, M.W. Wong, C. Gonzalez, J.A. Pople, Gaussian 03, Revision B.01, Gaussian, Inc., Pittsburgh, PA, 2003.

37- J.B. Foresman, T.A. Keith, K.B. Wiberg, J. Snoonian, M.J. Frisch, J. Phys. Chem., 1996, 100, 16098-16104.

38- G.A. Jaffrey, an Introduction to Hydrogen Bonding, Oxford University Press, 1997, 32.

39- S. Sudha, N. Sundaraganesan, K. Vanchinathan, K. Muthu, SP. Meenakshisundaram, J. Mol. Struct., 2012, 1030, 191-203.

40- R.M. Issa, M.K. Awad, F.M. Atlam, Appl. Surf. Sci., 2008, 255, 2433-2441.

41- D. Jacquemin, J. Preat, E.A. Perpete, Chem. Phys. Lett., 2005, 410, 254-259.

42- D. Jacquemin, J. Preat, M. Charlot, V. Wathelet, J.M. Andre, E.A. Perpete, J. Chem. Phys., 2004, 121, 1736-1743.

43- M. Cossi, V. Barone, J. Chem. Phys., 2001, $115,4708-4717$.

44- T. Minami, M. Nakano17th June 2016 , F. Castet, J. Phys. Chem. Lett., 2011, 2, 17251730.

45- K. Okuno, Y. Shigeta, R. Kishi, M. Nakano, Chem. Phys. Lett., 585 (2013) 201-206.

46- R. Baer, 1E. Livshits, U. Salzner, Rev. Phys. Chem., 61 (2010) 85-109.

47- T.Stein, H. Eisenberg, L. Kronik, R. Baer, Phys. Rev. Lett.,2010,105, 266802

48- N. Prabavathi, A. Nilufer, V. Krishnakumar, Spectrochim. Acta, Part A, 2014, 121, 483-493. 